\title{
Evaluation of serum Resistin in children with chronic renal failure undergoing hemodialysis
}

Abd El-Hamid Salah Al-Hamshary ${ }^{1}$, Osama Saad El-Shaaer², Doaa Refaay Soliman³ ${ }^{3}$ Ghada Mohamed ElMashad $^{4}$ Ahmed Ibraheem Hussien ${ }^{5}$

${ }^{1}$ MD, Pediatrician, Professor, the Pediatric Department, Faculty of Medicine, Benha University, Egypt

${ }^{2}$ MD, Clinical Pathologist, Professor, Clinical Chemical Pathology Department, Faculty of Medicine, Benha University, Egypt

${ }^{3}$ MD, Pediatrician, Assistant Professor, the Pediatric Department, Faculty of Medicine, Benha University, Egypt

${ }^{4}$ MD, Pediatrician, Assistant Professor, the Pediatric Department, Faculty of Medicine, Menoufia University, Egypt

${ }^{5}$ M.Sc. of Pediatrics, Pediatrician, the Pediatric Department, Faculty of Medicine, Benha University, Egypt

\section{Type of article: Original}

\begin{abstract}
Introduction: High serum resistin levels are associated with the incidence of chronic kidney disease (CKD). The objectives of this study were to determine the serum concentrations of resistin in children that present with chronic renal failure (CRF) and end stage renal disease (ESRD), in order to examine the impact of hemodialysis (HD) on serum resistin levels, and to determine if a correlation exists between resistin and growth retardation in patients with CRF.

Methods: This case control study was undertaken in the pediatric hemodialysis unit of the Benha and Menoufia University hospitals from April 2014 to March 2015. The case group consisted of 50 patients with CRF aged from 6-18 years ( 25 of them under HD and 25 of them under conservative treatment) and 30 healthy children who constituted the control group. Urea, creatinine, and serum resistin were measured before and after the HD session for patients with CRF who are already under HD.

Results: A highly significant difference was found between the resistin levels in the two groups with mean level of $20.2 \pm 7.58 \mathrm{ng} / \mathrm{ml}$ in the patient case group as compared to $4.9 \pm 1.72 \mathrm{ng} / \mathrm{ml}$ in the control group. This highly significant difference found in the resistin level differed according to the Chronic Kidney Disease (CKD) stage of progression as patients on regular HD had resistin levels with a mean of $24.6 \pm 7.28 \mathrm{ng} / \mathrm{ml}$ while the CKD patients under conservative treatment have resistin level mean of $15.6 \pm 4.72 \mathrm{ng} / \mathrm{ml}$. there was a highly significant difference in resistin levels before HD (mean $=24.6 \pm 7.28$ ) and after hemodialysis (mean $=14.7 \pm 5.2$ ).

Conclusion: Patients with CRF experienced higher than normal resistin levels as compared to the case control group and it was found that patients on HD had more elevated levels of resistin than did those patients who were on conservative treatment. HD treatments were found to be capable of lowering a patient's resistin levels. A highly significant negative correlation was found between serum resistin levels and the two contributing factors of total body weight and body mass index (BMI) as well as demonstrating a significant negative correlation between serum resistin levels and height percentiles.
\end{abstract}

Keywords: Resistin; Hemodialysis; Chronic renal failure; Children

\section{Introduction}

Chronic Renal Failure (CRF) is a serious result of a severe paediatric congenital and/or acquired kidney diseases. In the most severe cases it often leads to the need for hemodialysis, which presents further complications for the patients' clinical outcome. CRF compromises children's growth and puberty, glycometabolic and lipid homeostasis, nutritional health status, and the endocrine profile (1). Resistin is a cysteine-rich plasma protein (CRISPs), which belongs to a family of polypeptides compounds called resistin-like molecules that are integral in regulating energy

\section{Corresponding author:}

Ahmed Ibraheem Hussien, The Pediatric Department, Faculty of Medicine, Benha University, Egypt.

Tel: +201066040207, E-mail: dr.miiiido@hotmail.com

Received: March 10, 2016, Accepted: May 31, 2016, Published: July 2016

iThenticate screening: May 31, 2016, English editing: June 18, 2016, Quality control: July 04, 2016

(C) 2016 The Authors. This is an open access article under the terms of the Creative Commons Attribution-NonCommercialNoDerivs License, which permits use and distribution in any medium, provided the original work is properly cited, the use is non-commercial and no modifications or adaptations are made. 
homeostasis and carbohydrate-lipid metabolism (2). Serum levels of certain cell signaling proteins (adipocytokines) are altered by renal failure and this may have important metabolic implications given that the dramatic effect that such a loss of renal mass may have on the serum elimination of these substances, immediate associations between these adipocytokines and adipose tissue are not evident in all CRF patients. The altered adipocytokine balance in CRF patients may not only contribute to metabolic disturbances in the regulation of glucose as well as in lipid metabolism, but they may also play a part in the development of insulin resistance, inflammation, and atherosclerosis (3). The objectives of this research were to identify the typical serum concentrations of resistin in children with CRF and ESRD, to investigate the potential effects of $\mathrm{HD}$ on serum resistin levels, and to determine if any statistically significant correlation exists between resistin and growth retardation in patients with CRF.

\section{Material and Methods}

\subsection{Study design}

For this case control study, 50 children with CRF were selected from the pediatric HD unit of Benha and Menoufia University hospitals and 30 apparently healthy children were selected to constitute the control group from April 2014 to March 2015. The study was approved by ethical committee at Faculty of Medicine, Benha University.

\subsection{Subjects}

The participants were divided into 2 groups consisting of the case groups and the control groups. Case (patient) group, consisted of 50 children who were diagnosed as CRF and divided as: A) 25 patients undergoing regular HD, consisting of 12 males and 13 females aged 6 to 18 years, and B) 25 patients undergoing conservative treatment, consisting of 15 males and 10 females aged from 6 to 18 years. As well, 30 apparently healthy children of matched age and sex, 19 males and 11 females aged from 6 to 18 years, constituted the control group.

\subsection{Inclusion and exclusion criteria}

This study's cases were selected in accordance with the following inclusion and exclusion criteria. The inclusion criteria for participants were that they were patients with CRF (eGFR $20-75 \mathrm{ml} / \mathrm{min} / 1.73 \mathrm{~m}^{2}$ ) or that they were under dialysis and were from the ages of 6 to 18 years. Patient participants were excluded from this study if they had any other medical conditions that could possibly affect their resistin level. Therefore, patients were excluded if they had a severe infection such as peritonitis or sepsis, were undergoing treatment that would lead to anorexia or growth retardation except for CRF, had any medical history of disease that could affect liver function, had tumors, had congestive heart failure, were receiving immunosuppressive treatment, or were taking steroids.

\subsection{Methods}

All groups were required to provide a full medical history with special stress on the cause of the chronic renal impairment, disease duration, dialysis duration, dietetic history, and type of filter that is used for their hemodialysis. Their clinical examination and the anthropometric measures were taken, which included weight, height and body mass index (BMI) and subsequently the results were used to populate matricies showing percentiles for the categories of age and sex. The laboratory analyses that were conducted included serum urea, serum creatinine, estimation of glomerular filtration rate (GFR), and serum resistin.

\subsection{Statistical Analysis}

This study's results were organized, tabulated, and statistically analyzed using SPSS version 16 (SPSS Inc., Chicago, Illinois, USA). The researchers chose to use t-test, Mann-Whitney U Test, and Chi square test for data analysis.

\section{Results}

Upon examining the socio-demographic data from the patients in our study, it revealed that there was no significant difference between the three groups with regard to age and sex ( $\mathrm{p}$ value $=0.16$ and 0.49 respectively) as shown in Table 1. Comparing the resistin level between patient and control groups revealed that there was a highly significant statistical difference between the two groups with a mean level of $20.2 \pm 7.58 \mathrm{ng} / \mathrm{ml}$ in the patient group as compared to $4.9 \pm 1.72 \mathrm{ng} / \mathrm{ml}$ in the control group $(\mathrm{p}<0.001)$ as shown in Table 2 . The reserachers also found that there is a highly significant statistical difference in the resistin level with respect to the CKD stage as shown in Table 3 and Figure 1 since patients on regular HD typically have a resistin level with a mean of $24.6 \pm 7.28 \mathrm{ng} / \mathrm{ml}$ while CKD patients who are under conservative treatment tend to have a resistin level with a mean of $15.6 \pm 4.72$ $\mathrm{ng} / \mathrm{ml}(\mathrm{p}<0.001)$. In the group receiving hemodyalisis, there were found to be some highly significant negative correlations between serum resistin and BMI, with the BMI percentile being $(r=-0.704, p<0.001)$ and $(r=-0.639$, 
$\mathrm{p}<0.001$ ) while there was also found to be some significant negative correlations between the serum resistin and weight, as well as serum resistin and height.

Table 1. Demographic data of the studied groups

\begin{tabular}{|c|c|c|c|c|c|c|c|c|}
\hline \multicolumn{2}{|l|}{ Variable } & \multicolumn{2}{|c|}{ Dialysis patients $(\mathrm{n}=25)$} & \multicolumn{2}{|c|}{ Conservative patients $(\mathrm{n}=25)$} & \multicolumn{2}{|c|}{ Controls $(n=30)$} & $\mathrm{p}$-value \\
\hline \multicolumn{2}{|c|}{ Age (year); Mean \pm SD } & \multicolumn{2}{|c|}{$12.9 \pm 4.3$} & \multicolumn{2}{|c|}{$11.0 \pm 3.2$} & \multicolumn{2}{|c|}{$11.8 \pm 3.2$} & 0.16 \\
\hline \multirow[t]{2}{*}{ Sex; n (\%) } & Male & 12 & 48.0 & 15 & 60 & 19 & 63.3 & \multirow[t]{2}{*}{0.49} \\
\hline & Female & 13 & 52.0 & 10 & 40.0 & 11 & 36.7 & \\
\hline
\end{tabular}

Table 2. Resistin level of the studied groups

\begin{tabular}{|l|l|l|l|l|l|l|l|}
\hline Variable & \multicolumn{4}{l}{ Patients (n=50) } & \multicolumn{2}{l|}{ Controls (n=30) } & -value \\
\cline { 2 - 7 } & Mean & SD & Median (Range) & Mean & SD & Median (Range) & $<0.001$ \\
\hline Resistin $(\mathrm{ng} / \mathrm{ml})$ & 20.2 & 7.58 & $18.9(8-45)$ & 4.9 & 1.72 & $5(2.1-9.1)$ & \\
\hline
\end{tabular}

Table 3. Resistin level of the studied patients according to CKD stage

\begin{tabular}{|c|c|c|c|c|c|c|c|c|c|}
\hline \multirow[t]{2}{*}{ Variable } & \multicolumn{2}{|c|}{ Dialysis patients } & \multicolumn{2}{|c|}{ Conservative patients } & \multicolumn{2}{|c|}{ Controls } & \multirow[t]{2}{*}{ KWT } & \multirow[t]{2}{*}{ p-value } & \multirow[t]{2}{*}{ Significant pairs } \\
\hline & Mean & SD & Mean & SD & Mean & SD & & & \\
\hline Resistin & 24.6 & 7.28 & 15.6 & 4.72 & 4.9 & 1.72 & 63.5 & $<0.001$ & $\begin{array}{l}\mathrm{G} 1 \mathrm{~A} \neq \mathrm{G} 2 \\
\mathrm{G} 1 \mathrm{~B} \neq \mathrm{G} 2 \\
\mathrm{G} 1 \mathrm{~A} \neq \mathrm{G} 1 \mathrm{~B}\end{array}$ \\
\hline
\end{tabular}

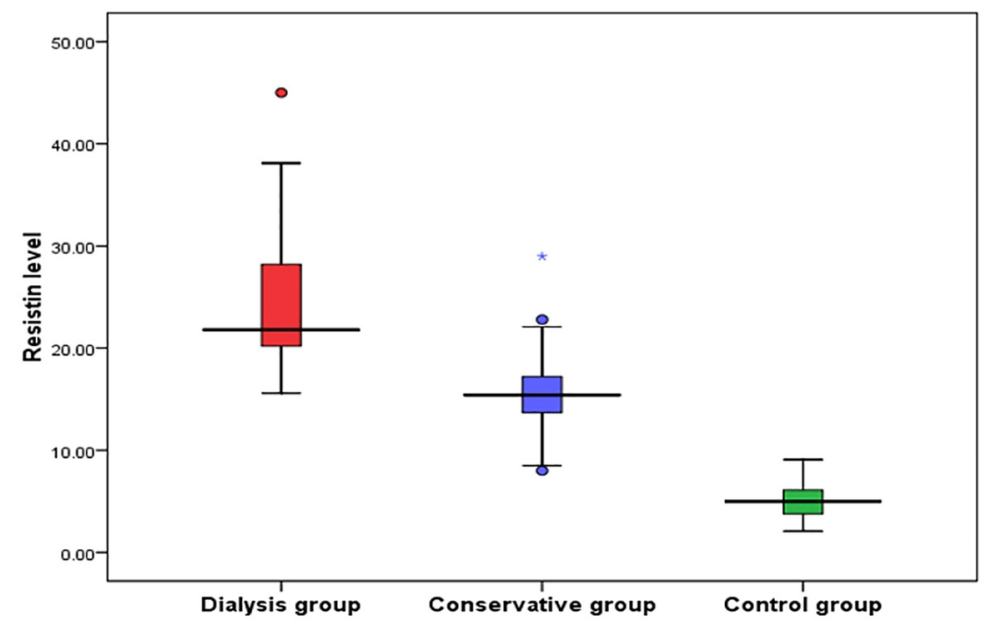

Figure 1. Box plot showing the resistin level among the studied groups

The weight percentile and height percentile were found to be $(r=-451, p=0.024),(r=-0.398, p=0.048)$; and the serum resistin and height percentiles were found to be $(r=-0.469, p=0.018)$, and $(r=-0.40, p=0.043)$. On the other hand, in the conservative group there was significant negative correlation with regard to weight, BMI, weight percentile, BMI percentile $(r=-0.487, p=0.016),(r=-0,507, p=0.01)$, as well as $(r=-0.491, p=0.013)$ and $(r=-0.442$, $\mathrm{p}=0.027$ ) respectively. But, there was a non-significant negative correlation as regard to height and height percentile $(\mathrm{r}=-0.0296, \mathrm{p}=0.15)$ and $(\mathrm{r}=-0.146, \mathrm{p}=0.027)$ as shown in Table 4 . With regard to the correlation between resistin level and renal function tests among CKD patients, the researchers found, as Table 5 illustrates, that in the hemodialysis group, there was found to be a highly significant correlation between resistin and the estimated Glomerular Filtration Rate (eGFR), a non-significant negative correlation between the resistin and the duration of hemodialysis and a non-significant positive correlation between resistin and both urea and creatinine $(\mathrm{p}<0.001, \mathrm{p}=$ $0.23, p=0.69$, and $p=0.53$ respectively); while in the conservative group, there was found to be a significant negative correlation between resistin and the eGFR as well as a non-significant positive correlation between resistin and both urea and creatinine $(\mathrm{p}=0.014, \mathrm{p}=0.6, \mathrm{p}=0.17$ respectively) as shown in Table 5 . With regard to the influence of hemodialysis on serum resistin levels, we found that there was a highly significant difference in the resistin levels before in comparision to after hemodialysis in dialysis patients and a highly significant difference in the resistin levels before dialysis among dialysis patients within the control group. Additionally, there was a highly significant difference in the resistin level after dialysis among dialysis patients within the control group. 
http://www.ephysician.ir

Table 4. Correlation between Resistin level and anthropometric measurement among the studied patients

\begin{tabular}{|l|l|l|l|l|}
\hline \multirow{2}{*}{ Anthropometric variables } & \multicolumn{3}{l}{ Resistin } \\
\cline { 2 - 5 } & \multicolumn{2}{|l|}{ Dialysis patients } & \multicolumn{2}{l|}{ Conservative patients } \\
\cline { 2 - 5 } & Rho & p-value & Rho & p-value \\
\hline Weight & -0.451 & 0.024 & -0.487 & 0.016 \\
\hline Height & -0.398 & 0.048 & -0.296 & 0.15 \\
\hline BMI & -0.704 & $<0.001$ & -0.507 & 0.01 \\
\hline Weight percentile & -0.469 & 0.018 & -0.491 & 0.013 \\
\hline Height percentile & -0.408 & 0.043 & -0.146 & 0.48 \\
\hline BMI percentile & -0.639 & 0.001 & -0.442 & 0.027 \\
\hline
\end{tabular}

Table 5. Correlation between resistin level and renal function among the studied patients

\begin{tabular}{|l|l|l|l|l|}
\hline \multirow{2}{*}{ Renal function variables } & \multicolumn{3}{l|}{ Resistin } \\
\cline { 2 - 5 } & \multicolumn{2}{l|}{ Dialysis patients } & \multicolumn{2}{l|}{ Conservative patients } \\
\cline { 2 - 5 } & Rho & p-value & Rho & p-value \\
\hline Urea & 0.082 & 0.69 & 0.103 & 0.62 \\
\hline Creat & 0.133 & 0.53 & 0.283 & 0.17 \\
\hline eGFR & -0.650 & $<0.001$ & -0.485 & 0.014 \\
\hline Duration of dialysis & -0.246 & 0.23 & ----- & ----- \\
\hline
\end{tabular}

\section{Discussion}

CKD is a worldwide public health concern and is a major risk factor for the development of ESRD, cardiovascular events, and a host of other complications that can encourage the likelihood of premature death. Identifying and treating the risk factors for this medical condition is certainly a valuable approach to discourage such a devastating clinical outcome (4). Recently, newly recognized molecules that are secreted by adipose tissue and have come to be known as adipokines, have been linked to the incidence of CKD. Among these signal molecules is resistin, a 12.5 $\mathrm{kDa}$ cysteine-rich protein (CRISP), which is also coinsidentally and abundantly secreted by macrophages. According to the literature, high serum resistin levels have been associated with kidney dysfunction, including low GFR (1). With regard to socio-demographic factors, this study has uncovered that among the 50 patient case group that was investigated, there were 27 male patients constituting $54 \%$ and 23 female patients constituting $46 \%$ of the patient case group. This study's results coincide with Naseri (5) who found that the gender distribution among CRF patients was $58.7 \%$ for males and $41.3 \%$ for females. Additionally, this study concurs with Pruthi (6) who found that the gender distribution among CRF patients was $57.7 \%$ for males and $42.3 \%$ for females. On the contrary, Nusken (7) found in his small-sized study on 15 patients with ESRD who were treated by HD that the percentage of male patients was $38.4 \%$ and percentage of female patients was $61.6 \%$. With regard to the resistin levels in our study, the serum resistin levels were found to be significantly higher in patients with CRF $(20.2 \pm 7.58 \mathrm{ng} / \mathrm{ml})$ than in the case control group $(4.9 \pm 1.72 \mathrm{ng} / \mathrm{ml})(\mathrm{p}<0,001)$, and they were also found to be significantly higher in patients with ESRD on regular HD $(24.6 \pm 7.28 \mathrm{ng} / \mathrm{ml})$ than in patients on conservative therapy $(15.6 \pm 4.72 \mathrm{ng} / \mathrm{ml})(\mathrm{p}<0.001)$. As well, there was a significant difference between their levels before and after the HD session in group 1A, and yet there was still a significant difference between the resistin levels after the HD session in group 1A as when this group is compared to the levels in group $2(\mathrm{p}<0.001)$. The elevated resistin level in patients as compared to the controls is small, but slightly higher than what was obtained by Nehus (8) who found that resistin level had a mean of $18.7 \mathrm{ng} / \mathrm{ml}$. As well, this research investigation agrees with the results obtained by Malyszko (9) and Diez (10) who found that the resistin level is markedly elevated in CKD patients in relation to healthy children. Malyszko and Diez stated that the kidney is an important location for resistin elimination from the body. Higher resistin levels were found in patients who were on regular HD than those patients who were placed under conservative treatment. This finding was quite similar to those obtained by Axelsson (3) who demonstrated that resistin levels are higher in children with CKD under regular HD when compared to those with CKD under a conservative treatment. In their study, Axelsson found that the mean of resistin level was $39.9 \pm 1.3 \mathrm{ng} / \mathrm{ml}$ in HD patients and $23.2 \pm 1.0 \mathrm{ng} / \mathrm{ml}$ for patients in the conservative group. In contrast, this research study conflicted in its findings with Maggio (1) who found that there was no statistically significant difference in the resistin levels in pediatric patients with CKD versus case controls as well Maggio reported that normal levels of resistin were found in their patients and that this was simply an expression of an adequate nutritional and metabolic status in addition to acontrolled inflammatory state; therefore, resistin could be a useful diagnostic indicator for the follow-up of these patients. 
In this study in the HD group, highly significant negative correlations were found between the serum resistin and both BMI and the BMI percentile was $(\mathrm{r}=-0.704, \mathrm{p}<0.001)$ and $(\mathrm{r}=-0.639, \mathrm{p}<0.001)$; while there were significant negative correlations between the serum resistin and the weight, height, and the weight percentile and the height percentile $(r=-451, p=0.024),(r=-0.398, p=0.048),(r=-0.469, p=0.018)$ and $(r=-0.40, p=0.043)$ respectively. On the other hand, in the conservative group, there was found to be a significant negative correlation with regard to weight, BMI, the weight percentile, the BMI percentile $(r=-0.487, p=0.016),(r=-0.507, p=0.01),(r=-0.491, p=$ $0.013)$ and $(r=-0.442, p=0.027)$ respectively. However, there was non-significant negative correlation with regard to the height and the height percentile $(r=-0.0296, p=0.15)$ and $(r=-0.146, p=0.027)$. This research study's results were supported by Yannakoulia (11) who studied the dynamic between the resistin level and body fat mass in healthy individuals and reported that serum resistin levels were negatively correlated with BMI and body fat in young participants. This study's results were also supported by Youn (12) who found that plasma the resistin concentrations demonstrated a negative correlation with BMI. Also, Briffa (13) and Dan (14) reported a negatively significant correlation between the serum resistin levels and BMI. Briffa and Dan submitted that resistin has been shown to be influenced by BMI. In the study conducted by Maggio (1), they found that $13 \%$ of patients with CKD had a BMI < 10th percentile, $58 \%$ had a BMI between the 10th-85th percentile and $23 \%$ had BMI $>85$ th percentile in contrast to our study's findings. Yet, it is important to point out that, there was no statistically significant difference in resistin levels between CKD patients versus controls. In contrast to our study, Nehus (8) reported that that the resistin level is correlated to patient's maturational development rather than with their anthropometric parameters, such as age and BMI. Additioanlly, Silha (15) found that resistin did not correlate at all with BMI when looking at the correlation between resistin and kidney functions tests in CRF patients. Contrastingly, in this present study, we found that within the HD group, there was a highly significant correlation between resistin levels and eGFR, while there were non-significant negative correlations between resistin and duration of dialysis and a nonsignificant positive correlation between resistin and both urea and creatinine $(p<0.001, p=0.23, p=0.69$, and $p$ $=0.53$, respectively). While in the conservative group, there was found to be a significant negative correlation between resistin and eGFR as well as a non-significant positive correlation between resistin and both urea and creatinine $(p=0.014, p=0.6$, and $p=0.17$, respectively). The present study coincides with the findings of Maggio (1) who suggested that serum resistin levels tend to increase as the levels of GFR decrease, which is involved in the milieu of inflammatory response that is present in CRF. This present study also agreed with the research conducted by Nehus (8) whose findings showed that serum resistin level tend to increase with progressively declining kidney function in children with CKD. Likewise, our study concurs with Zein (16) who found that there was a nonsignificant positive correlation between resistin level and serum creatinine $(r=0.092, p=0.574)$ level, nevertheless in contrast to our study, their results demonstrated that there was a positive correlation between resistin level and the duration of HD ( $r=0.351, p=0.027)$. In agreement with this study's results, Pilz (17) found that resistin plasma concentration was, in fact, correlated with urea and creatinine. In addition, Axelsson (3) found that elevated serum resistin levels in CKD can be associated with decreased eGFR since they reported that there was highly statistically negative correlation between serum resistin and eGFR $(\mathrm{r}=-0.54, \mathrm{p}<0.001)$. Similarly Nehus $(8)$ reported that serum resistin levels were negatively correlated with GFR $(P<0.01)$. Just like Kielstien (18) who concluded that serum resistin levels tended to increase with progressive impairment of renal function and that resistin plasma concentrations were significantly negatively correlated to the GFR. Therefore, it is supported by extant research studies that the kidney is generally considered to be an important site for Resistin elimination.

With reference to the influence of HD on resistin levels, this study found that there was a highly significant difference in resistin levels when comparing before (mean=24.6 \pm 7.28$)$ and after hemodialysis (mean $=14.7 \pm 5.2)$ in HD patients $(\mathrm{p}<0.001)$ and highly a significant difference in resistin levels before dialysis among HD patients as compated with the controls (mean= $4.9 \pm 1.72 ; \mathrm{p}<0.001$ ). Moreover, there was highly significant difference in the resistin levels after dialysis among HD patients as compared to the controls $(p<0.001)$. Filippidis (19) concurred with our study in that the pre-dialysis resistin serum levels were significantly greater in HD patients as compared to healthy case controls; however, he disagreed with our study in that HD did not modify resistin levels, since the preand post-dialysis levels were found to be the same when corrected for hemoconcentration. The difference between our results and those that were gathered by Filippidis (19) could be a result of the difference in the type of the dialyzing membrane used in the HD sessions since in our study, we used filter called "Fresenius Polysulfone ${ }^{\circledR}$ based dialysers" while Filippidis used a modified cellulose membrane in their study. Fresenius Polysulfone Low-Flux Filters are more effective than modified cellulose membrane as Carracedo (20) and Horl (21) reported that such cellulose filters can induce inflammatory reactions in certain patients, complement activation, and produce proinflammatory cytokines and interleukines such as IL-1 $\beta$ and TNF- $\alpha$, furthermore Bowry (22) documented that polysufone dialyzers have definite intrinsic biocomptability, low cytotoxicity and efficient removal of broad 
spectrum of uremic toxins. Additionally in their research, Nusken (7) found that serum resistin levels tended to be higher in HD compared to healthy controls and that HD did not significantly eliminate them. This disagreement with our results could be related to the HD regimen used by Nusken or by the type of filters were used.

\section{Conclusions}

Resistin levels were elevated in the researcher's patients with CRF more than the case control group and their levels were also elevated in the patients who were on HD more than those patients on the conservative treatment. HD sessions have been found to significantly reduce the levels of resistin, but the patient's levels after the HD session were still higher than what was found in the case control group, so the HD session was still found to be an ineffective treatment in reducing their levels to what would be considered a normal level as demonstrated by the case control group. There was a highly significant negative correlation between the serum risitin level and both the weight and the BMI percentiles as well as a significant negative correlation between the serum resistin level and the height percentiles. The researchers suggest that further studies should concentrate on the effect of elevated serum levels of resistin on CRF and how it affects CRF stage progression. The research reveals that the treatment of growth retardation in children with CRF should center on the treatment of anemia and the correction of any electrolyte and acid-base imbalance that may be present, renal osteodystrophy, in addition to any other complications of CRF. Furthermore, greater attention should be placed on the development of new modalities of HD in order to compensate for compromised renal function in the removal of small sized adipokines and signaling molecules such as resistin to avoid them having any negative health ramification when accumulated in the body.

\section{Acknowledgments:}

The researchers would like to thank all the patients, the physicians who participated in the study, the parents of the patients, and the nursing staff, your assistance was integral to the success of this research endeavor.

\section{Conflict of Interest:}

There is no conflict of interest to be declared.

Authors' contributions:

All authors contributed to this project and article equally. All authors read and approved the final manuscript.

\section{References:}

1) Maggio MC, Montaperto D, Maringhini S, Corrado C, Gucciardino E, Corsello G. Adiponectin, resistin and leptin in paediatric chronic renal failure: correlation with auxological and endocrine profiles. J Nephrol. 2014; 27(3): 275-9. doi: 10.1007/s40620-013-0015-2. PMID: 24449263.

2) McTernan PG, McTernan CL, Chetty R, Jenner K, Fisher FM, Lauer MN, et al. Increased resistin gene and protein expression in human abdominal adipose tissue. J Clin Endocrinol Metab. 2002; 87(5): 2407. doi: 10.1210/jcem.87.5.8627. PMID: 11994397.

3) Axelsson J, Bergsten A, Qureshi AR, Heimbürger O, Bárány P, Lönnqvist F, et al. Elevated resistin levels in chronic kidney disease are associated with decreased glomerular filtration rate and inflammation, but not with insulin resistance. Kidney Int. 2006; 69(3): 596-604. doi: 10.1038/sj.ki.5000089. PMID: 16395259.

4) Chou HH, Lin CY, Chiou YH, Tain YL, Wang YF, Wang HH, et al. Clinical characteristics and prevalence of complications of chronic kidney disease in children: the Taiwan Pediatric Renal Collaborative study. Pediatr Nephrol. 2016; 31(7):1113-20. doi: 10.1007/s00467-016-3325-5. PMID: 26850057.

5) Naseri M, Mottaghi Moghadam Shahri H, Horri M, Esmaeeli M, Ghaneh Sherbaf F, Jahanshahi S, et al. Absolute and Relative Carnitine Deficiency in Patients on Hemodialysis and Peritoneal Dialysis. Iran J Kidney Dis. 2016; 10(1): 36-43. PMID: 26837680.

6) Pruthi R, Casula A, Inward C, Roderick P, Sinha MD, British Association for Paediatric Nephrology. Early Requirement for RRT in Children at Presentation in the United Kingdom: Association with Transplantation and Survival. Clin J Am SocNephrol. 2016; 11(5): 745-802. doi: 10.2215/CJN.08190815. PMID: 26912550.

7) Nüsken KD, Kratzsch J, Wienholz V, Stöhr W, Rascher W, Dötsch J. Circulating resistin concentrations in children depend on renal function. Nephrol Dial Transplant. 2006; 21(1): 107-12. doi: 10.1093/ndt/gfi084. PMID: 16144855.

8) Nehus E, Furth S, Warady B, Mitsnefes M. Correlates of Resistin in Children with Chronic Kidney Disease: The Chronic Kidney Disease in Children Cohort. J Pediatr. 2012; 161(2): 276-80. doi: 10.1016/j.jpeds.2012.01.055. PMID: 22421264, PMCID: PMC3553545. 
9) Malyszko J, Malyszko JS, Kozminski P, Pawlak K, Mysliwiec M. Elevated resistin is related to inflammation and residual renal function in haemodialysed patients. Nephrology (Carlton). 2007; 12(3): 246-53. doi: 10.1111/j.1440-1797.2007.00782.x. PMID: 17498119.

10) Díez JJ, Iglesias P, Fernández-Reyes MJ, Aguilera A, Bajo MA, Alvarez-Fidalgo P, et al. Serum concentrations of leptin, adiponectin and resistin, and their relationship with cardiovascular disease in patients with end-stage renal disease. Clin Endocrinol (Oxf). 2005; 62(2): 242-9. doi: 10.1111/j.13652265.2005.02207.x. PMID: 15670203.

11) Yannakoulia M, Yiannakouris N, Blüher S, Matalas AL, Klimis-Zacas D, Mantzoros CS. Body fat mass and macronutrient intake in relation to circulating soluble leptin receptor, free leptin index, adiponectin, and resistin concentrations in healthy humans. J Clin Endocrinol Metab. 2003; 88(4): 1730-6. doi: 10.1210/jc.2002-021604. PMID: 12679465.

12) Youn BS, Yu KY, Park HJ, Lee NS, Min SS, Youn MY, et al. Plasma resistin concentrations measured by enzyme-linked immunosorbent assay using a newly developed monoclonal antibody are elevated in individuals with type 2 diabetes mellitus. J Clin Endocrinol Metab. 2004; 89(1): 150-6. doi: 10.1210/jc.2003-031121. PMID: 14715842.

13) Briffa JF, McAinch AJ, Poronnik P, Hryciw DH. Adipokines as a link between obesity and chronic kidney disease. Am J Physiol Renal Physiol. 2013; 305(12): 1629-36. doi: 10.1152/ajprenal.00263.2013. PMID: 24107418.

14) Dan S, Aditya P, Banerjee P, Bal C, Roy H, Banerjee I. Effect of chronic kidney disease on serum resistin level. Niger J Clin Pract. 2014; 17(6): 735-8. doi: 10.4103/1119-3077.144387. PMID: 25385911.

15) Silha JV, Krsek M, Skrha JV, Sucharda P, Nyomba BL, Murphy LJ. Plasma resistin, adiponectin and leptin levels in lean and obese subjects: correlations with insulin resistance. Eur J Endocrinol. 2003; 149(4): 331 5. doi: 10.1530/eje.0.1490331. PMID: 14514348 .

16) Zein MY, Abdel-Salam M, Abdel-Aziz I, Fathy Mohamed N. Serum Resistin Level and Polymorphonuclear Leukocytes Dysfunctions in Children on Regular Hemodialysis. International Journal of Clinical Medicine. 2015; 6(6): 423-30. doi: 10.4236/ijcm.2015.66055.

17) Hoffmann MM, Pilz S, Weihrauch G, Seelhorst U, Wellnitz B, Winkelmann BR, et al. Effect of the resistin $-420 \mathrm{C}>\mathrm{G}$ polymorphism on cardiovascular disease and mortality. Clin Endocrinol (Oxf). 2008; 69(2): 344-5. doi: 10.1111/j.1365-2265.2007.03163.x. PMID: 18167137.

18) Kielstein JT, Becker B, Graf S, Brabant G, Haller H, Fliser D. Increased resistin blood levels are not associated with insulin resistance in patients with renal disease. Am J Kidney Dis. 2003; 42(1): 62-6. doi: 10.1016/S0272-6386(03)00409-8.

19) Filippidis G, Liakopoulos V, Mertens PR, Kiropoulos T, Stakias N, Verikouki C, et al. Resistin serum levels are increased but not correlated with insulin resistance in chronic hemodialysis patients. Blood Purif. 2005; 23(6): 421-8. doi: 10.1159/000088017. PMID: 16141714.

20) Carracedo J, Ramírez R, Madueño JA, Soriano S, Rodríguez-Benot A, Rodríguez M, et al. Cell apoptosis and hemodialysis-induced inflammation. Kidney Int Suppl. 2002; 80: 89-93. doi: 10.1046/j.15231755.61.s80.17.x. PMID: 11982820.

21) Horl WH. Hemodialysis Membranes: Interleukins, Biocompatibility, and Middle Molecules. J Am Soc Nephrol. 2002; 13: 62-71. PMID: 11792764.

22) Bowry SK, Gatti E, Vienken J. Contribution of polysulfone membranes to the success of convective dialysis therapies. Contrib Nephrol. 2011; 173: 110-8. doi: 10.1159/000328960. PMID: 21865783. 